\title{
BLOCKCHAIN, DIGITAL MUSIC AND LEX MERCATORIA
}

\author{
Ewa Fabian*
}

\begin{abstract}
The publication analyses the development of the music industry in the context of blockchain technology, containing an overview of possible areas of application and general advantages. Given the current lack of appropriate legislation, the prolonging value gap and growing transactions costs may prompt the market to develop bottom-up pieces of regulation, sometimes referred to as lex mercatoria (self-regulation of the industry). The issues faced by the music industry are analyzed in the context of transaction costs, based on research commissioned by the institutions of the European Union.
\end{abstract}

INTRODUCTION 852

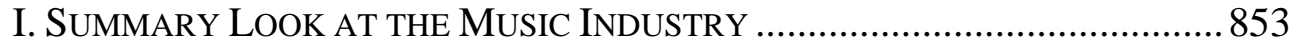

II. ColleCtIVE MANAGEMENT ORGANIZATIONS (CMOS) ............................854 III. REPORTS LEADING TO THE MULTI-TERRITORIAL LICENSING OF MUSICAL

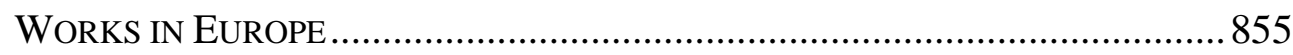

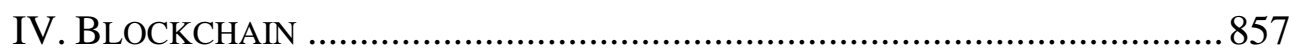

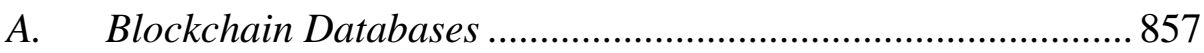

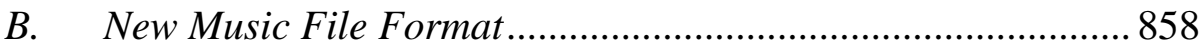

C. Micropayments and Smart Contracts Platforms ...................... 859

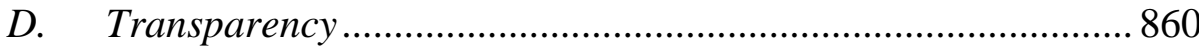

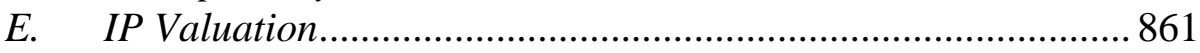

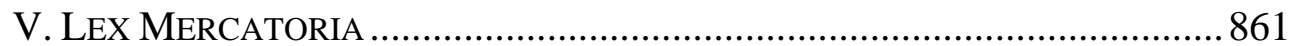

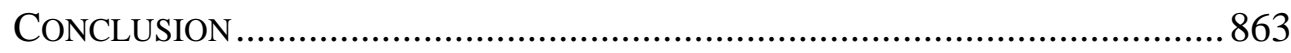

\section{INTRODUCTION}

The music industry has been the pioneer of the digital innovation ${ }^{1}$ and experienced dramatic change as a result of digitalization that triggered the internet economy. ${ }^{2}$ It has the potential to be an important "first adoption" platform for new technology, such as blockchain, and to set trends.

\footnotetext{
${ }^{*}$ Attorney at law qualified to practice in Poland. Research field: private law. Associated with FREE Institute (Fundacja Rozwoju Edukacji Elektronicznej) established by Dr hab. P. P. Polanski, Professor of law at Kozminski University.

${ }^{1}$ Christophe Waignier, Blockchains et smart contracts: premiers retours d'expérience dans l'industrie musicale, ANNALES DEs Mines-RÉALITÉs INDUSTRIELLES (2017/3).

${ }^{2}$ Andreas Gabi \& Stephan Ulrich Krehl, Application of Blockchain Technology and Crowdfunding to Solve Structural Inefficiencies in Digital Rights and Patent-A Comparative Analysis, Mit SLOAN SCHOOL OF MANAGEMENT 100 (2017).
} 


\section{SUMMARY LOOK AT THE MUSIC INDUSTRY}

According to the New York Times (2016), "the big sales numbers that have sustained the recorded music business for years are way down, and it is hard to see how they could ever return to where they were even a decade ago". The shrinking sales have been caused by a range of activities of online users. In 2017, the industry reported a small growth. According to the IFPI Report 2017, "[b]efore seeing a return to growth in 2015, the global recording industry lost nearly 40\% in revenues from 1999 to 2014", with the global recorded music revenues totaling US $\$ 15.7$ billion, rising by $5.9 \%$ on $2015 .{ }^{4}$ The growth of streaming revenue was reported at $60.4 \%$. Streaming (i.e., offered by digital companies such as Spotify) took up the majority of revenue in digital sales $(59 \%)$; the digital revenue took up half of the global music industry market. The new status quo is that music is accessed more or mainly through streaming services.

The standard way of producing music with big label companies usually involved exclusive recording contracts between the companies and the artists. Artists assigned all copyright to the label company for any music they created while the contract was in effect. They often shared commercial risk - the costs the company incurred to eventually bring the music to the market were in the end paid for by the artist from the earnings their records brought. An example has been reported over Mick Hucknall's split with Warner Music: "Hucknall told a newspaper it was wrong that despite him having paid recording and marketing costs, the record company still owned the master tapes". 5 Today, when entering the website of the British digital distribution and label services company AWAL (owned by the Kobalt Music Group), ${ }^{6}$ the aspiring artist sees: "Flexible Deal. You keep 100\% of your rights, we never lock you in or take any upfront fees. It's just 15\% of your revenue, so we only make money when you do-a true partnership". When analyzing this shift in business models, it is important to remember that labels often act similarly to an investor: "Labels act like venture capitalists, who provide musicians financial resources as well as a network of support. Record companies finance the recording of tracks and get engaged in distribution of copies to stores and digital platforms. Labels also

\footnotetext{
${ }^{3}$ Ben Sisario \& Karl Russell, In Shift to Streaming, Music Business has Lost Billions, THE NEw YoRK TIMES (2016).

${ }^{4}$ Global Music Report 2017: Annual State of the Industry, InTERnATIONAL FEDERATION OF THE PHONOGRAPHIC INDUSTRY (2017).

${ }^{5}$ Hucknall Attacks Music Industry, BBC News (2003).

${ }^{6}$ Wikipedia (January 2018).

${ }^{7}$ https://awal.com (January 2018).
} 
promote artists (...). In doing so, labels take an up-front risk, as the commercial success of artists is difficult to determine." ${ }^{8}$ It will be interesting to see if artists prefer to rely on online networks and fan bases, including the possibility of crowdfunding and licensing their creations directly or rather seek the support of investors such as label companies.

\section{Collective Management ORganizations (CMOs)}

Collective Management Organizations (CMOs) operate on the basis of national and international legislation. Their purpose is to collectively license works on the terms they negotiate, monitor the use, collect revenue and redistribute it among right holders. ${ }^{9}$ They also act as lobbying organizations, representing members in the public debate and in pushing for effective protection. ${ }^{10}$ Because of CMOs, artists holding their copyrights may be remunerated directly.

From the legal perspective intellectual property rights ought to be central to the development of the arts. The international copyright protection system has been introduced in the $19^{\text {th }}$ century (the Berne Convention for the Protection of Literary and Artistic Works of 1886), the collective rights managements for performers and producers - in 1960 in Europe $;{ }^{11}$ now, most works created since then have been enveloped in a specific legal background. However, legislation we have today has been created and enacted in a different reality, before the digital era: before the internet, digital databases and ledgers, Big Data analytics and on-line payments.

As the music industry is becoming more digital and global, copyright protection systems have remained territorial and country-specific. As Schroff and Street (2017) put it: "those who use the internet to distribute music legally, for example via streaming services, find themselves having to deal with multiple agencies, leading to high transaction costs (...) In a borderless digital world, the national monopoly status of the CMO has become increasingly cumbersome for those seeking to licence works for multi-territorial use", and give the example of GEMA (a CMO based in Germany) which allowed streaming of music via YouTube only after seven

\footnotetext{
${ }^{8}$ Andreas Gabi \& Stephan Ulrich Krehl, Application of Blockchain Technology and Crowdfunding to Solve Structural Inefficiencies in Digital Rights And Patent - a Comparative Analysis, MIT SLOAN SCHOOL OF MANAGEMENT 106-107 (2017).

${ }^{9}$ Simone Schroff \& John Street, The Politics of the Digital Single Market: Culture vs. Competition vs. Copyright, InFORMATION, COMMUNICATION \& SOCIETY (2017).

${ }^{10}$ Ibidem, with original source quotations, at 11 .

${ }^{11}$ Ibidem, at 13 .
} 
years of legal dispute. ${ }^{12}$

Intermediaries such as CMOs handling the distribution of royalties operate under different sets of rules (common and civil legal regimes showing most differences), have different works portfolios, different reach, authorization, effectiveness, etc. The system which has been developing for over a century now cannot be overlooked: Spotify has been sued over streaming music for which it has only a part of the license rights (e.g., the license to stream recordings but not the compositions, as in the case brought against Spotify by Wixen at the end of 2017). ${ }^{13}$

One may argue that the global digital music industry requires a smaller number of intermediaries for the distribution of music to work. It also needs a more fitting technology, as well as a more fitting legal framework. However, the task of regulating new technology may be compared to putting paved paths on the building site. When it is not known yet how future users will walk around, it is almost impossible to determine where the paths should be placed. It may be better to watch where people actually walk and then build pavements, for the ease and safety of pedestrians, according to customary use. Of course, this simple example overlooks the fact that many industries are in almost constant development.

\section{REPORTS LEADING TO THE MULTI-TERRITORIAL LICENSING OF MUSICAL WORKS IN EUROPE}

As a part of the Digital Single Market policy, the European Union has analyzed the challenges and hurdles of collective management of copyright for several years; the reports led to the EU to the introduction of the 10 April 2016 Collective Rights Management Directive no. 2014/26/EU (CRM Directive).

One of the research reports, the 2006 KEA Report pointed, inter alia, to fragmentation and territoriality of rights: "the European entertainment/cultural market is characterised by its fragmentation along linguistic and cultural frontiers. This fragmentation is reinforced by the territorial nature of the rights." ${ }^{14}$ The report emphasizes that the collective management "enables right owners and users to jointly access lower transaction costs" and that "[m]onopoly societies in this sense serve

\footnotetext{
${ }^{12}$ Ibidem, at 4.

${ }^{13}$ Andrew Flanagan, Sweeping New Music Law Expedites A \$1.6 Billion Lawsuit Against Spotify, NPR (2018).

${ }^{14}$ The Collective Management of Rights in Europe. The Quest for Efficiency, KEA EUROPEAN AFFAIRS 16 (2006).

${ }^{15}$ Ibidem, at 6 .
} 
efficiency because they are the only way to overcome the high transaction costs of administering millions of works and thousands of users" ${ }^{16}$ On the other hand: "[authors] want to understand the money flow and take the view that the societies shield them from the power of large publishers. They also want strong societies capable of standing up to powerful media companies". ${ }^{17}$ It has been argued by scholars that outdated and incompatible databases are one of the weak points of the CMOs (becoming the so-called "black box"). ${ }^{18}$

KEA Report issued in $2012^{19}$ focused on transactions costs, which "include all the costs incurred when a transaction takes place" ${ }^{20}$ The document mentions transaction costs connected with identification (identifying the right owners), negotiation (with CMOs or record producers and publishers) and monitoring (the costs of making sure the contract is complied with). In 2012, identification costs were found to still be challenging for online music services. The report identified such causes: fragmentation of rights among various right owners: a single track will be covered by authors' rights (composer and lyricist), performers' rights (singer(s) and musician(s)), the record producer and the music publisher (if they acquire the rights from the right owners by transfer). ${ }^{21}$ Another issue is the uncertainty of rights ownership, i.e. lack of appropriate information often leading to double payment or even several payments for the same track. ${ }^{22}$ Whether the fragmentation of works is described as above or by reference to the rights of control (reproduction control, distribution control, performance control and communication control) ${ }^{23}$ or to any separate rights or fields of exploitation ${ }^{24}$ - it is likely to remain the biggest obstacle for any attempts of international legislation.

Importantly from the perspective of blockchain applications, the 2012 report provides: "Creative Commons licences introduce flexibility in licensing processes by anticipating the terms and uses permitted by

\footnotetext{
${ }^{16}$ Ibidem, at $18-19$.

${ }^{17}$ Ibidem, at 18 .

${ }^{18}$ Andreas Gabi \& Stephan Ulrich Krehl, Application of Blockchain Technology and Crowdfunding to Solve Structural Inefficiencies in Digital Rights and Patent - a Comparative Analysis, MIT SLOAN SCHOOL OF MANAGEMENT 111 (2017).

${ }^{19}$ Licensing Music Works and Transaction Costs in Europe. Final Study, KeA EuROPEAN AFFAIRS (2012).

${ }^{20}$ Ibidem, at 4.

${ }^{21}$ Ibidem, at 25.

${ }^{22}$ Ibidem, at 5.

${ }^{23}$ Andreas Gabi \& Stephan Ulrich Krehl, Application of Blockchain Technology and Crowdfunding to Solve Structural Inefficiencies in Digital Rights and Patent - a Comparative Analysis, MIT SLOAN SCHOOL OF MANAGEMENT 104 (2017).

${ }^{24}$ Using here the term existing in the Polish jurisdiction.
} 
copyright holders. Moreover, licensing terms are immediately recognisable thanks to the human-readable (the Commons Deed), lawyer-readable (the Legal Code), machine-readable (metadata) language attached to the work. Ex ante transaction costs are therefore eliminated for noncommercial uses". ${ }^{25}$

Despite the 2014 CRM Directive being prepared on the basis of thorough research, including the above reports, in 2017, the digital music market is still at the stage where proper legislation is reported to be missing. According to 2017 IFPI Report there still exists: "the global 'value gap', whereby 'safe harbour' legislation dating from the Internet's early days is being abused by user (...) (...) the European Commission has recognised the existence of a value gap and begun working towards legislation. However, this is a global problem that requires legislative solutions across the globe $"{ }^{26}$ Some criticism of the 2014 CRM Directive has been expressed by scholars, in particular with regard to the chosen solution: "we have noted (...) that the Commission has resorted to its default policy instrument of increased competition. Our study has revealed that this approach leads to significant policy weaknesses that impact negatively on stakeholders (...) The result is a system which is unlikely to serve the smaller (and, in practice, the vast majority of) right holders to the same extent that it will benefit larger and more successful ones". ${ }^{27}$

\section{BLOCKCHAIN}

According to the analyses (including O'Dair 2016) ${ }^{28}$, there are a few main applications for blockchain in music: a networked database for music copyright information; a new file format; fast, frictionless royalty payments and access to alternative sources of capital; transparency and a way to reevaluate IP rights.

\section{A. Blockchain Databases}

The idea of a networked database is related to the fact that blockchain is not stored in a single database but in a decentralized one where every participant of the network should at each moment have a copy of the same

\footnotetext{
${ }^{25}$ Licensing Music Works and Transaction Costs in Europe. Final Study, KEA EUROPEAN AFFAIRS 3839 (2012).

${ }^{26}$ Global Music Report 2017: Annual State of the Industry, InTERNATIONAL FEDERATION OF THE PHONOGRAPHIC INDUSTRY (2017).

${ }^{27}$ Simone Schroff, John Street, The Politics..., 13.

${ }^{28}$ Marcus O'Dair et al., Music on the Blockchain, BlOCKCHAIN FOR CREATIVE INDUSTRIES RESEARCH CLUSTER (Middlesex University 2016).
} 
ledger. According to research (Sevelyev 2017), networked databases are promising in the copyright context: "Using different proprietary databases, which are not interoperable with each other is one of the obstacles for datasharing (...) blockchain technology may (...) bring standardization and network effects in the sphere of copyright management". ${ }^{29}$ In particular, such databases may decrease the transaction costs associated with the process of identification.

However, copyright under the Berne Convention (1886) does not require registration of works. Storing copyright information on a blockchain could lead to a regime requiring every work to be time-stamped in the digital database. ${ }^{30}$ If a digital decentralized database emerges, it is also important to raise questions whether it would apply to all existing works. Another question would be how to avoid disparities among right owners and digital discrimination, how to treat blockchain evidence in case of disputes, how to protect copyright effectively and how quickly would the right owners become aware of an infringement. As Sevelyev (2017) points out: "although judges will have to pass some period of acclimatization for such kinds of evidence, like for any new types of evidence based on technical innovation". ${ }^{31}$ It is interesting to see that large CMOs have already begun working towards a metadata blockchain database solution (some in cooperation with IBM) and are sharing information about it at a relatively early stage. $^{32}$

\section{B. New Music File Format}

The O'Dair Report brings the example of the Dot Blockchain Music initiative by Benji Rogers, whose idea is to store copyright information on a certain format, introduce a trusted database and preferably lead to the emergence of a new digital music file, addressing the existing issues by changing the very asset. ${ }^{33}$ According to researchers, the blockchain makes it

\footnotetext{
${ }^{29}$ Alexander Savelyev, Copyright in the Blockchain Era: Promises and Challenges, Higher School of Economics Research Paper No. WP BRP 77/LAW/2017 (2017).

${ }^{30}$ Ignatio De Leon \& Ravi Gupta, The Impact of Digital Innovation and Blockchain on the Music Industry, Institutions for Development Sector, Inter-American Development Bank, discussion paper NoIDB-DP-549, p. 27 (2017).

${ }^{31}$ Alexander Savelyev, Copyright in....

${ }^{32}$ ASCAP, SACEM and PRS For Music Initiate Joint Blockchain Project to Improve Data Accuracy for Rightsholders, ASCAP, April 7, 2017; Christophe Waignier, Blockchains et smart contracts: premiers retours d'expérience dans l'industrie musicale, ANNALES DES MINES-RÉALITÉS INDUSTRIELLES, 2017/3.

${ }^{33}$ Stuart Dredge, Benji Rogers on Blockchain: "We Can't Rush This. It's Worth Getting Right", Music ALLY (2017).
} 
possible to "hash things such as art or software to prove authorship of the works" (Swan 2015). ${ }^{34}$

According to Bobby Owsinski, the new format is not likely to succeed since streaming is the way we now consume music. He claims that "[f] ormats like Mini-disc, digital compact cassette, Super Audio CD (SACD) and DVD-Audio Disc were an effort to sell people yet another round of product they already owned. They offered no added convenience to the consumer (the audio quality was better, but that's never been a driving factor with music delivery formats) and all failed miserably". In his view, blockchain as a file format provides no consumer advantage and therefore is not likely to replace on-line streaming. ${ }^{35}$

In the context of information databases and "wrappers", the O'Dair Report poses the important question who would "enter the data" and "who would verify it". ${ }^{36}$ It is often stated that blockchain technology eliminates intermediaries. ${ }^{37}$ However, arguably, the introduction of blockchain technology, even though it is decentralized by definition, would not necessarily eliminate intermediaries. It would either introduce a new intermediary (such as the blockchain provider and the associated network) or would need to be interwoven into the existing copyright regimes (involving the distribution of royalties by the CMOs). This is also important in light of the fact that blockchain innovation in the US "has led to something of a patent rush, with numerous patent applications being filed for blockchain-related inventions in the last few years". ${ }^{38}$ Elimination of some intermediaries is likely to bring new intermediaries, even if such new ones operate under different tools and standards, have different roles, objectives or structure (such as a decentralized network) than the ones they replace.

\section{C. $\quad$ Micropayments and Smart Contracts Platforms}

Blockchain may allow payment directly to the right owner and such option could also stimulate "tips" and other bonuses. The O'Dair Report makes a point about "low transaction costs of cryptocurrencies". This is not

\footnotetext{
${ }^{34}$ Melanie Swan, Blockchain: Blueprint for a New Economy, O'ReILLY (2015).

${ }^{35}$ Bobby Owsinski, Despite Predictions, Blockchain Will Not Be the Future of the Music Industry, FORBES (2017).

${ }^{36}$ Marcus O'Dair et al., Music on the Blockchain, BlOCKCHAIN FOR CREATIVE INDUSTRIES RESEARCH CLUSTER 9 (Middlesex University 2016).

${ }^{37}$ Marco Iansiti \& Karim R. Lakhani, The Truth about Blockchain, HARVARD Business REVIEW (2017).

${ }^{38}$ Hiroshi Sheraton \& Birgit Clark, Blockchain and IP: Crystal Ball-Gazing or Real Opportunity?, THOMSONREUTERS PRACTICAL LAW (2017).
} 
always the case: time shows that transaction costs for cryptocurrencies may significantly rise ${ }^{39}$ low transaction costs are not an integral, ever-present part of blockchain systems. Another issue is that digital currencies are currently used by a very small fraction of the population. The use of micropayments for the music industry relies mainly on the development of cryptocurrencies. The historical attempts of the use of cryptocurrencies by musicians when releasing their music (Imogen Heap ${ }^{40}$ and $\mathrm{REC}^{41}$ ) are an important milestone. O'Dair (2017) points out that a mixed (hybrid) approach to the issue may be key:

It may be that the future lies in hybrid platforms such as OCL (One-Click License), which clears usage rights for any media (thus allowing legal remixes and "mash-ups") and encourages micropayments for content via a combination of blockchain and centralized technologies. ${ }^{42}$

\section{Transparency}

The idea of transparency is linked to the fact that public blockchains are open, which is possible because of sophisticated verifying mechanisms. It is a new approach to the management of data compared to any traditional-even digital-databases. Transparency relates to the relationship between authors or performers with the CMOs, labels and online music providers. It appears especially important when coming across such views: "U2 singer Bono also broached the issue in Rolling Stone magazine (...), saying the problem was not the new digital technologies such as Spotify. "When people pick on Spotify: Spotify are giving up 70\% of all their revenues to rights owners. It's just that people don't know where the money is because the record labels haven't been transparent," he said". ${ }^{43}$ However, it is not clear how such transparency could be put into place - as a result of storing music on a blockchain file format or by other methods, perhaps as a result of methods allowing CMOs and large companies (labels, streaming companies etc.) to store data efficiently and transparently share it.

\footnotetext{
${ }^{39}$ Ryan Browne, Big Transaction Fees Are a Problem for Bitcoin-but There Could Be a Solution, CNBC (2017).

${ }^{40}$ Imogen Heap, Blockchain Could Help Musicians Make Money Again, HARVARD BuSINESS ReviEW (2017).

${ }^{41}$ Bill DeLisle, The First Blockchain Album Release, CRYPTOSLATE (2017).

${ }^{42}$ Marcus O'Dair \& Zuleika Beaven, The Networked Record Industry: How Blockchain Technology Could Transform the Record Industry, 26 (5) STRATEGIC CHANGE, BRIEFINGS IN ENTREPRENEURIAL FINANCE 475 (2017).

${ }^{43}$ Ralf Brechter, Using Blockchain for Media Rights Management and Ad Revenues, DigitaLISTMAG (2017).
} 


\section{E. IP Valuation}

The final general application, according to the IDS Report $(2017)^{44}$ is related to the fact that a digitalized asset ledger would be able to track (in real time) the popularity of a given piece of music: "[t]he dynamic assessment of music usage could allow for greater flexibility in IP valuation" 45 and to re-evaluate compositions. The authors of the IDS Report point out that upcoming artists have to rely on access terms of the large streaming music providers. Being able to see how the track is developing would "allow an artist to set their own rate or perhaps even superior price optimization models through smart contracts".

\section{LEX MERCATORIA}

Lex mercatoria is usually referred to as laws established by bottom-up adoption, not by an act of legislator. It is known by its ability to provide rules where the legislator fails to regulate. The difficult obligation put on the music industry to reconciliate several jurisdictions was noticed by Sevelyev (2017) who then referred to the widely used Creative Commons license. The Creative Commons initiative founded in 2001 was created "mainly by US law professors" ${ }^{47}$ basing on the idea ${ }^{48}$ of the Free Software Movement founded by Richard Stallman ${ }^{49}$ and has been adopted worldwide as part of the open source movement to ease of use of digital content by the global online community.

It has been stated that online technology brought a new kind of economy (Lessig 2008): the hybrid economy, "suited to reflect current trends in global online interaction" where participants on the one hand "'shared' their free time, knowledge, ideas, offered each other companionship and support-free of charge", and on the other: "free

\footnotetext{
${ }^{44}$ Ignatio De Leon, Ravi Gupta, The Impact of Digital Innovation and Blockchain on the Music Industry, Institutions for Development Sector, Inter-American Development Bank, discussion paper NoIDB-DP-549 (2017).

${ }^{45}$ Ibidem, at 23.

${ }^{46}$ Ibidem, at 23.

${ }^{47}$ Axel Metzger, Transnational Law for Transnational Communities: The Emergence of a Lex Mercatoria (or Lex Informatica) for International Creative Communities, 3 J. INTELL. PROP. INFO. TECH. \& ELEC. COM. L. 361 (2012).

${ }^{48}$ LAWRENCE LESSIG, CC IN REVIEW: LAWRENCE LESSig On How IT AlL BEgAN, creativecommons.org (2005).

${ }^{49}$ Lawrence Lessig, Open Code and Open Societies: Values of Internet Governance, 74 CHI.-KENT. L. REV. 1405 (1999).
} 
sharing also brought tremendous commercial success". ${ }^{50}$ At the same time it should be remembered that "the objective of the regulation of crossborder contracts is rather the reduction of transaction costs originating in the 'constitutional uncertainty' of foreign trade that flows from the coexistence of a great number of uncoordinated legal systems". ${ }^{51}$ It may be observed that the cross-border community now requires a relatively small degree of certainty to operate, yet it develops certain bottom-up soft law solutions. Notably, some of these self-adopted practices were aimed at providing a higher degree of certainty and security, e.g. the use of cryptography by IT developers, by 2007 requiring "at least using the Secure Sockets Layer (SSL) version 3.0 protocol (or higher)(...) with a 128-bit encryption". 52

Being an example of an adopted, though not state-regulated, practice, the Creative Commons license has been fulfilling many of the objectives of the lex mercatoria. "The traditional lex mercatoria theory is based on the idea that the international community of traders has developed over time a body of internationally customary rules independent from the law of specific states (...) one could argue that open source communities have developed a body of independent rules of law that are accepted in the community". ${ }^{53}$ Importantly, many blockchain projects (including Bitcoin, Ethereum and Hyperledger) are built and operated on open-source codes.$^{54}$ What is more, in the economy build on cross-border commerce, the main concern is that of trust; according to researchers: "the blockchain infrastructure of cryptocurrencies may change this. Self-executing smart contracts already enable trustless contractual relationships (...) gradual decline of trust is the difference between older models of private governance and blockchain technologies" ${ }^{55}$ This statement may become important in the coming years, since reputation (and the associated trust) has probably played an important role in the emergence of lex mercatoria: "reputation would have to be

\footnotetext{
${ }^{50}$ Joanna Kulesza \& Roy Balleste, Signs and Portents in Cyberspace: The Rise of Jus Internet as a New Order in International Law, 23 FordHAM INTELL. Prop. MEdia \& ENT. L. J. 1311 (2013), quoting Lawrence Lessig, Remix: Making Art and Commerce Thrive in the Hybrid Economy (2008).

${ }^{51}$ Jurgen Basedow, Lex Mercatoria and the Private International Law of Contracts in Economic Perspective, 12 UNIF. L. REV. n.s. 697 (2007).

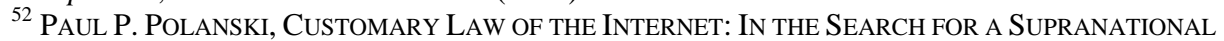
Cyberspace Law (T. M. C. Asser Press, The Hague 2007).

${ }^{53}$ Axel Metzger, Transnational Law for Transnational Communities the Emergence of a Lex Mercatoria (or Lex Informatica) for International Creative Communities, 3 JIPITEC 361 (2012).

${ }^{54}$ Christopher Tozzi, What Blockchain and Open Soirce Software Share in Common, CHANNEL FUTURES (2017).

${ }^{55}$ Riikka Koulu, Blockchains and Online Dispute Resolution: Smart Contracts as an Alternative to Enforcement, 13 SCRIPTED 40 (2016).
} 
considered as the relevant enforcement mechanism for the rules of conduct of the modern lex mercatoria. Reputation functions as an enforcement mechanism when it is likely to meet a transaction partner again (Axelrod 1984) (...) business relations are mainly based on a handshake or 'common honesty and decency' (1963, p. 58), even in transactions bearing considerable risk". ${ }^{56}$ The question of emerging bottom-up regulations certainly calls for further research.

\section{CONCLUSION}

The image of the digital music industry shown in the reports and analyses presents several opportunities for blockchain technology applications, such as addressing the issue of fragmentation of rights and the lack of effective, transparent and fair standard practices. Currently, even legislation preceded by thorough analysis appears to be too slow or inadequate. In such circumstances, the processes defined by the balancing of transaction costs are even more likely to determine the future. The possibility to eliminate existing intermediaries is likely to give room for new intermediaries, with different roles but nevertheless important for the integrity of the entire working system. Rapid growth and a significant need for a self-imposed standard may lead to an adoption of a new approach by the market participants without interference from the legislator (such a phenomenon is usually described as lex mercatoria). The example of the Creative Commons license, quoted by several authors in this context, may be key to understanding how new technology fits into the social as well as legal and economic backgrounds. It is not impossible to imagine a blockchain solution finding its way into music. In this industry, it is not difficult to maintain the fundamental purposes of the system-balancing the protection of the creative process and, at the same time, the existence of participants of the chain which eventually brings the music to the listener. Whether blockchain may become a new form or iteration of the lex mercatoria-remains to be researched.

\footnotetext{
${ }^{56}$ Oliver Volckart \& Antje Mangels, Are the Roots of the Modern Lex Mercatoria Really Medieval?, 65(3) SOUTHERN ECONOMIC JOURNAL 427-450 (1999).
} 